\title{
Complementary and alternative treatment methods for menopausal \\ hot flashes used in Turkey \\ Handan Ozcann ${ }^{1}$, Pınar Çolak ${ }^{1}$, Berna Oturgan², Esra Gülsever ${ }^{2}$
}

\author{
1. University of Health Sciences, Faculty of Health Sciences, Department of Midwifery. Mekteb-i Tibbiye-i \\ Şahane, Selimiye mah. Tibbiye Cad. No: 38, 34668 Üsküdar/ İstanbul, Turkey. ORCİD ID: 0000-0002-7131-1856 \\ 2. Gumushane University, Department of Nurse.
}

Emails: Handan Ozcan: hndnozcn@hotmail.com; Pınar Çolak: colakp96@gmail.com; Berna Oturgan: bernaoturgan38@gmail. com; Esra Gülsever: esragulsever21@gmail.com

\begin{abstract}
Objective: Study was planned to determine complementary and alternative treatment methods for menopausal hot flashes.

Methods: Women who reported their discomfort of hot flashes as a degree of discomfort of 4 or more according to the Visual Analogue Scale (VAS) were included in the study (n:356). In data collection, Questionnaire Form and Complementary and Alternative Medicine Approaches Scale were used.

Results: The average age of the women was $56.65 \pm 6.05$ and the average age of menopause was $46.39 \pm 5.25$. According to VAS, the average severity of hot flashes was $7.85 \pm 1.83$.

Women with obesity and any chronic disease were more likely to have hot flashes. It was determined that $73.6 \%$ of women in the menopausal period were using Complementary and Alternative Medicine (CAM). It was determined that women were using herbal supplements, dietary supplements, mind-body practices and religious practices against the discomfort of hot flashes. $72 \%$ of women using CAM stated that the method used was effective.

Conclusions: Women who use CAM usually use it with information that is out of the knowledge of health profession and lack of information. It is recommended to carry out extensive studies for CAM methods and the mechanisms of action that women use.
\end{abstract}

Keywords: Menopause, hot flashes, complementary and alternative medicine.

DOI: https://dx.doi.org/10.4314/ahs.v19i4.21

Cite as: Ozcan H, Colak P, Oturgan B, Gülsever E. Complementary and alternative treatment methods for menopausal hot flashes used in Turkey. Afri Health Sci.2019;19(4):3001-3008. bttps:/ / dx.doi.org/10.4314/abs.v19i4.21

\section{Introduction}

Menopause is the longest life stage, in which psychological and social changes, as well as physical changes, are experienced in a woman's lifespan. In this stage of life, some health problems may arise, too. ${ }^{1}$

Although menopause starts in women at a mean age of 51 years, the onset of symptoms occurs usually 10 years earlier (perimenopausal symptoms). The distinguishing

\section{Corresponding author:}

Handan Ozcan,

University of Health Sciences, Faculty of Health

Sciences, Department of Midwifery.

Mekteb-i Tibbiye-i Şahane,

Selimiye mah. Tibbiye Cad. No: 38, 34668

Üsküdar/ İstanbul, Turkey.

ORCID ID: 0000-0002-7131-1856

Email: ndnozcn@hotmail.com symptoms of menopause include vasomotor symptoms; especially hot flashes and night sweating. Hot flashes are characterized by a feeling of a sudden and intense sense of heat starting in the chest and extending over the entire chest and neck; ${ }^{2}$ and they are reported as the most common and troublesome experiences. The hormonal changes in menopause include a sharp rise in the circulating luteinizing hormone levels and in the levels of epinephrine (a potent stimulator of heart, which increases the heart rate, systolic blood pressure, and cardiac output); and a simultaneous decline in the levels of hormone norepinephrine (which increases blood pressure significantly). ${ }^{3}$ There has been little examination of the parasympathetic branch in hot flashes. Although the increased heart rate previously observed to accompany hot flashes has often been assumed to be sympathetically mediated, manifest changes in heart rate may be the result of decreased parasympathetic influences (delivered to the heart via the vagus nerve), increased sympathetic cardiac control, or both. ${ }^{4}$

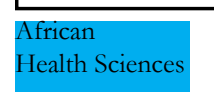

(C) 2019 Ozcan et al. Licensee African Health Sciences. This is an Open Access article distributed under the terms of the Creative commons Attribution License (https://creativecommons.org/licenses/BY/4.0), which permits unrestricted use, distribution, and reproduction in any medium, provided the original work is properly cited.

African Health Sciences Vol 19 Issue 4, December, 2019 
Hot flashes are the most common symptoms during the climacterium and occur in about $75 \%$ of postmenopausal and perimenopausal women in Western societies. ${ }^{5}$ However, the prevalence varies by country; being $75 \%$ in the United States, ${ }^{6} 10 \%$ in Hong-Kong, ${ }^{7} 62 \%$ in Australia, ${ }^{8}$ $68 \%$ in Canada, ${ }^{9}$ and almost $83 \%$ in Great Britain. ${ }^{10}$ The prevalence of hot flashes varies by the ethnic origin in the USA, beinmost common in African American women (45.6\%), followed by women with Spanish (35.4\%), Caucasus $(31.2 \%)$, Chinese $(20.5 \%)$, and Japanese (17.6\%) origins, respectively. ${ }^{11}$ Studies in Turkey report the rates of hot flashes as $72.7-80.4 \%$ and the night sweats as 70.1 $78.2 \% .^{12,13}$

Complaints of hot flashes also vary according to the cultural and ethnic structure. Cultural attitudes are influenced by family relations and social affiliations, as well as by the general condition of well-being and social status. ${ }^{14}$ Moreover, the intensity, frequency, severity and the duration of hot flashes vary from person to person. The SWAN study (Study of Women's Health Across the Nation), including 16.000 women, reported that hot flashes were seen in some women on a monthly or weekly basis, while they occurred more frequently in a daily or hourly routine in others. The majority of women reported that they had experienced hot flashes most frequently during a period of 6 months to 2 years after menopause. These symptoms lead to feelings of embarrassment, discomfort, and uneasiness and cause some problems like loss of sleep. ${ }^{15}$

The long-lasting discussions on the benefits and risks of hormone replacement therapy (HRT) over the last 15 years created some confusion among women. ${ }^{16}$ Menopausal women and many practitioners particularly consider HRT as an undesired intervention due to the concerns associated with the risk of developing breast cancer and vascular problems. ${ }^{17} \mathrm{~A}$ variety of treatment modalities are used for the treatment hot flashes. Studies have reported a range of Complementary and Alternative Medicine (CAM) therapies in menopausal women with primarily minerals and vitamins (such as vitamin E, vitamin C, multivitamins, and calcium), ${ }^{18-21}$ followed by herbal medicines, ${ }^{18,19,22}$ relaxation techniques/yoga, ${ }^{21,23}$ and dietary changes. ${ }^{18,23}$

CAM practices in symptom management include biologically-based methods, body-based therapies, mind-body medicine, energy therapies, and traditional methods. ${ }^{24}$
Because of the observed efficacy of various herbal remedies on vasomotor and psychosomatic symptoms of menopause in different studies, there is a growing body of research reporting that especially the plants containing phytoestrogens are effective in the alleviation of the symptoms. ${ }^{25}$

This study was planned to identify the complementary and alternative treatment methods used for the alleviation of hot flashes by menopausal women.

\section{Methods}

\section{Sampling technique and inclusion criteria}

The study population consisted of a total of 4721 women, who were in the age range from 40 to 65 years of age according to 2017 TSI (Turkish Statistical Institute) data, and who lived in the center of Gümüşhane province. ${ }^{26}$ The study sample was composed of women who were in menopause and who have not had menstrual bleeding in the last year, based on their self-reports. In the determined study universe and within a 95\% confidence interval, the number of women to be included in the study was calculated to be 356 according to the sampling formula and this figure was taken as the minimum sample volume. According to the determined sample volume, women were stratified into 5 -year age ranges $(40-44$ years $=91$ women, $45-49$ years $=75$ women, $50-54$ years $=84$ women, $55-59$ years $=54$ women, $60-64$ years $=50$ women).

\section{Data collection}

This cross-sectional study was conducted between January 2018 to May 2018 in a state hospital in Turkey, including women in the age range from 40 to 65, who applied to the outpatient clinic. As the hospital was the only public hospital in the city center, providing healthcare services covering the society almost completely, the study sample included eligible women who applied to the outpatient clinics of the hospital. The inclusion criteria were being in menopause, having hot flashes, and having a discomfort level of 4 or more scored on the Visual Analogue Scale (VAS) (a 10-point scale). The patients were excluded if they had any auditory or mental disabilities.

The study data were collected using a questionnaire comprising items investigating the socio-demographic characteristics and features of menopause. To identify the complementary and alternative methods used for hot flashes, "Complementary and Alternative Medicine Scale (CAMS)", developed by Can G et al. ${ }^{27}$, was used. The scale consists of five subgroups of 55 CAM inter- 
ventions frequently used. The five subgroups comprise the following; including the herbal supplement subgroup (29 items), biological practices subgroup ( 3 items), dietary supplement subgroup (14 items), religious practices subgroup (5 items), and mind-body practices subgroup (5 items). CAMS assesses the use of individual CAM methods by dichotomous responses, where 0 means "no" and 1 means "yes". Sub-dimension scores were calculated summing up the scores of individual items and the total score of the scale is the sum of individual sub-dimension scores. The Kuder-Richardson 20 (KR20) coefficient for the scale was $0.84 .{ }^{27}$

\section{Data analysis}

Descriptive statistics, median, mean, frequency, and percentages were used for summarizing the distribution of patient characteristics and features of menopause. The Mann-Whitney U and Kruskal Wallis tests were used in the assessment of factors affecting CAM use. All statisti- cal tests were two-sided and the significance level was set at 0.05 .

\section{Ethical considerations}

The required permission to conduct the study was obtained from the administration unit of the Health Directorate and from the Scientific Research and Publication Board of Gümüşhane University (Number: 95674917604.01.02-E.6100). Eligible women were informed about the study. Verbal consent was obtained from women, who accepted to participate in the study. Each woman was interviewed for 20 minutes to fill in the data collection questionnaire.

\section{Results}

The average age of the women was $56.65 \pm 6.05$ years and the average age of menopause onset was $46.39 \pm$ 5.25 years. Socio-demographic characteristics of the participants are presented in Table 1 . The majority of women were married housewives who graduated from primary school.

Table 1. Socio-demographic characteristics of the participants (n:356)

\begin{tabular}{lcclcc}
\hline Employment Status & $\mathbf{n}$ & $\mathbf{\%}$ & Marital Status & $\mathbf{n}$ & $\mathbf{\%}$ \\
\hline Housewife & 329 & 92.4 & Married & 304 & 82.3 \\
Retired/Employed & 27 & 7.6 & Single & 52 & 17.7 \\
Total & 356 & 100.0 & Total & 356 & 100.0 \\
\hline Educational Status & $\mathbf{n}$ & $\mathbf{\%}$ & Income Status & $\mathbf{n}$ & $\mathbf{\%}$ \\
\hline Literate & 148 & 42.4 & Less income than expense & 80 & 22.5 \\
Primary School & 148 & 42.4 & Equal income to expense & 232 & 65.1 \\
High School and above & 53 & 15.2 & More income than expense & 44 & 12.4 \\
Total & 349 & 100.0 & Total & 356 & 100.0 \\
\hline
\end{tabular}

The mean severity of hot flashes was scored as $7.85 \pm 1.83$ on VAS. The Body Mass Index (BMI) was over the normal weight in $86.8 \%$ of the participating women and $46.8 \%$ of them were classified as obese. Of the participants, $24.2 \%$ had undergone a gynecological surgery including hysterectomy or myomectomy. There were no significant differences between the presence of hot flashes, any gynecological diseases and a history of gynecological surgery $(p>0.05)$. It was determined that there were no significant differences between BMI and the presence of hot flashes, but the complaints were more severe in the obese group (VAS scores in the ideal weight group= $7.45 \pm 1.84$; overweight group $=7.78 \pm 1.87$; and obese group $=8.00 \pm 1.78)$.

The medical histories of the participating women informed that $86.3 \%$ of them had a vaginal delivery, $31.8 \%$ of them gave birth at home, 56.4\% suffered from a chronic disease (hypertension, diabetes, cholesterol, asth- ma, etc.), and $58.7 \%$ were on regular treatment with medications. It was determined that $56.5 \%$ of the participants did not receive any information about the menopause period and $57.7 \%$ of the informed women received information from a health professional. Of the menopausal women, $71.6 \%$ of women did not receive any medical support. In order to cope with hot flashes, $93 \%$ of the women practiced the following respectively, including deep breathing exercises (68\%), physical exercise (14\%), moving to a cooler environment $(68.3 \%)$, wearing thin clothes $(66.4 \%)$, consuming cold drinks $(20.8 \%)$, taking a luke-warm shower $(23.9 \%)$, and cold application to the feet $(31.5 \%)$.

In women with any chronic diseases (hypertension, diabetes, cholesterol etc.), the frequency of hot flashes was found to be significantly higher (U: 13432,500, p: 0,025). Characteristics of hot flashes experienced by the participants are summarized in Table 2. 
Table 2. Characteristics of hot flashes of the participants (n: 356)

\begin{tabular}{|c|c|c|c|c|c|}
\hline Start Time of the Complaints & $\mathbf{n}$ & $\%$ & Frequency of Hot Flashes & $\mathbf{n}$ & $\%$ \\
\hline $\begin{array}{l}\text { During the first year of menopause } \\
\text { period }\end{array}$ & 233 & 86.6 & 2-3 times a day & 154 & 43.3 \\
\hline $\begin{array}{l}\text { During the first five years of } \\
\text { menopause period }\end{array}$ & 28 & 10.4 & $\begin{array}{l}\text { Everyday } \\
2-3 \text { times a week }\end{array}$ & $\begin{array}{l}89 \\
64\end{array}$ & $\begin{array}{l}25.0 \\
18.0\end{array}$ \\
\hline During the entire menopause period & 8 & 3.0 & Once a month & 49 & 13.7 \\
\hline Total & 269 & 100.0 & Total & 303 & 100.0 \\
\hline Time of Complaints & $\mathbf{n}$ & $\%$ & Duration of Complaints & $\mathbf{n}$ & $\%$ \\
\hline Morning & 5 & 1.7 & $1-2$ minutes & 107 & 30.1 \\
\hline Noon & 18 & 5.9 & 3-5 minutes & 132 & 37.1 \\
\hline Evening & 33 & 10.9 & $10-15$ minutes & 68 & 19.1 \\
\hline Night & 73 & 24.1 & 20-30 minutes & 49 & 13.8 \\
\hline Irregular & 174 & 57.4 & Total & 356 & 100.0 \\
\hline Total & 303 & 100.0 & & & \\
\hline The Impact on Daily Activities & $\mathbf{n}$ & $\%$ & $\begin{array}{l}\text { Consulting a physician } \\
\text { for hot flashes }\end{array}$ & $\mathbf{n}$ & $\%$ \\
\hline Yes & 182 & 51.1 & Yes & 97 & 27.2 \\
\hline No & 174 & 48.9 & No & 259 & 72.8 \\
\hline Total & 356 & 100.0 & Total & 356 & 100.0 \\
\hline
\end{tabular}

Most of the hot flashes were experienced on the back $(26.7 \%)$, followed by the head/neck $(23.9 \%)$ region, and on hands/feet $(18.8 \%)$. In regards to the hot flashes they experienced; $84.8 \%$ of the participating women stated that sweating accompanied the hot flashes, $74.4 \%$ felt too uncomfortable waking up in the middle of the night, and 44.4\% experienced palpitations during hot flashes. Modes of CAM used for the treatment of hot flashes by the menopausal women are presented in Table 3.

Table 3. Use of CAM Therapies ${ }^{a}(\mathrm{n}: 356)$

\begin{tabular}{llllll}
\hline Herbal supplements & $\mathbf{n}$ & $\mathbf{\%}$ & Dietary supplements & $\mathbf{n}$ & $\mathbf{\%}$ \\
\hline Linden tea & 26 & 7.3 & Yoghurt & 170 & 47.8 \\
Rosehip & 19 & 5.3 & Milk and milk products & 81 & 22.8 \\
Daisy & 18 & 5.1 & Honey & 16 & 4.5 \\
Green tea & 15 & 4.2 & Carob syrup & 7 & 2.0 \\
Sage tea & 13 & 3.7 & Anzer/carob honey & 4 & 1.1 \\
Marjoram & 9 & 2.5 & Mullberry syrup & 6 & 1.7 \\
Stinging nettle & 9 & 2.5 & Sweet & 5 & 1.4 \\
Nigella sativa & 6 & 1.7 & Red meat & 4 & 1.1 \\
Ginger & 6 & 1.7 & Fish & 3 & 0.8 \\
Sweet almond & 2 & 0.6 & Chicken & 3 & 0.8 \\
Curcuma & 1 & 0.3 & Bread/pastry & 2 & 0.6 \\
Flax seed & 2 & 0.6 & Garlic & 6 & 1.7 \\
Vitamin & 3 & 0.8 & Carrot & 5 & 1.4 \\
Horsetail & 1 & 0.3 & Pomegranate & 3 & 0.8 \\
Grape seed & 3 & 0.8 & Grapefruit & 4 & 1.1 \\
Omega 3 & 2 & 0.6 & Other fruits and vegetables & 103 & 28.9 \\
Other (mint, onionskin, melissa, fennel...) & 17 & 4.8 & Other (peach, apple, molasses...) & 18 & 5.1 \\
\hline Mind-body practices & $\mathbf{n}$ & $\mathbf{\%}$ & Religious practices & $\mathbf{n}$ & $\mathbf{\%}$ \\
\hline Exercise & 35 & 9.8 & Namaz & 132 & 37.1 \\
Biological practices & - & - & Pray & 203 & 57.0 \\
\hline a Some patients used more than one CAM therapy so the percentages of CAM use are given according to the related item. & & &
\end{tabular}


It was determined that $73.6 \%$ (n: 262 ) of the menopausal women tried CAM. Most commonly used herbal remedies for the alleviation of the hot flashes included simmered teas made of linden, rosehip, daisy, green tea and sage. Fruits and vegetables, yoghurt, milk and milk products, and honey were the most commonly used dietary supplements. The participating women also reported that they performed mind-body exercises, ritual prayers of Islam religion, or they simply prayed. No patients performed biological practices like shark cartilage, turtle blood or rabbit blood (Table 4). Of the women trying CAM, 72\% stated that the method they were using was effective. Various factors associated with the use of complementary and alternative treatments in menopause are presented in Table 4.

Table 4. Comparison of sub-dimension and total score averages of CAM scale according to characteristics of the participants

\begin{tabular}{|c|c|c|c|c|c|c|c|}
\hline & & $\begin{array}{c}\text { Herbal } \\
\text { Approaches }\end{array}$ & Biological Approaches $^{\mathrm{a}}$ & $\begin{array}{l}\text { Nutritional } \\
\text { Approaches }\end{array}$ & $\begin{array}{c}\text { Religious } \\
\text { Approaches }\end{array}$ & $\begin{array}{c}\text { Spiritual } \\
\text { Approaches }\end{array}$ & Total \\
\hline \multirow{4}{*}{$\begin{array}{c}\text { Getting } \\
\text { Information } \\
\text { about } \\
\text { Menopause }\end{array}$} & Yes & $2.51 \pm 3.02$ & - & $2.39 \pm 2.35$ & $1.74 \pm 0.59$ & $1.00 \pm 00$ & $4.19 \pm 4.45$ \\
\hline & No & $3.00 \pm 1.65$ & - & $2.00 \pm 1.48$ & $1.63 \pm 0.50$ & $1.00 \pm 00$ & $3.38 \pm 2.14$ \\
\hline & $\mathbf{U}$ & 170.000 & 11340.000 & 3631.500 & 3259.500 & 168.000 & 5637.500 \\
\hline & $\mathbf{p}$ & .035 & 1.000 & .472 & .315 & 1.000 & .289 \\
\hline \multirow{4}{*}{$\begin{array}{l}\text { Suffering } \\
\text { from } \\
\text { Insomnia }\end{array}$} & Yes & $2.45 \pm 2.43$ & - & $2.15 \pm 1.85$ & $1.68 \pm 0.52$ & $1.00 \pm 00$ & $3.80 \pm 3.16$ \\
\hline & No & $3.87 \pm 3.27$ & - & $2.35 \pm 2.36$ & $1.67 \pm 0.66$ & $1.00 \pm 00$ & $3.61 \pm 4.43$ \\
\hline & $\mathbf{U}$ & 124.000 & 8120.000 & 2196.500 & 1887.000 & 150.000 & 3084.000 \\
\hline & $\mathbf{p}$ & .333 & 1.000 & .833 & .660 & 1.00 & .027 \\
\hline \multirow{4}{*}{$\begin{array}{l}\text { Consulting } \\
\text { a Physician }\end{array}$} & Yes & $2.41 \pm 1.73$ & - & $2.16 \pm 1.13$ & $1.76 \pm 0.42$ & $1.00 \pm 00$ & $4.00 \pm 2.11$ \\
\hline & No & $2.83 \pm 3.00$ & - & $2.19 \pm 2.21$ & $1.64 \pm 0.59$ & $1.00 \pm 00$ & $3.66 \pm 3.87$ \\
\hline & $\mathbf{U}$ & 260.000 & 9331.000 & 2851.500 & 2608.000 & 192.000 & 4093.500 \\
\hline & $\mathbf{p}$ & .937 & 1.000 & .161 & .077 & 1.000 & .014 \\
\hline \multirow{4}{*}{$\begin{array}{c}\text { The Impact } \\
\text { on Daily } \\
\text { Activities }\end{array}$} & Yes & $3.21 \pm 3.14$ & - & $2.43 \pm 2.43$ & $1.77 \pm 0.55$ & $1.00 \pm 00$ & $4.20 \pm 4.27$ \\
\hline & No & $1.95 \pm 1.35$ & - & $1.88 \pm 1.037$ & $1.54 \pm 0.50$ & $1.00 \pm 00$ & $3.18 \pm 1.73$ \\
\hline & $\mathbf{U}$ & 205.500 & 11371.000 & 3358.000 & 2724.000 & 198.000 & 5072.000 \\
\hline & $\mathbf{p}$ & .104 & 1.000 & .134 & .009 & 1.000 & .037 \\
\hline Getting & Yes & $3.00 \pm 2.36$ & - & $2.28 \pm 1.21$ & $1.72 \pm 0.45$ & $1.00 \pm 00$ & $3.67 \pm 2.34$ \\
\hline \multirow{3}{*}{$\begin{array}{l}\text { Medical } \\
\text { Help }\end{array}$} & No & $2.59 \pm 2.70$ & - & $2.15 \pm 2.17$ & $1.67 \pm 0.57$ & $1.00 \pm 00$ & $3.80 \pm 3.81$ \\
\hline & $\mathbf{U}$ & 187.000 & 9523.000 & 2583.500 & 2522.500 & 198.000 & 5076.000 \\
\hline & $\mathbf{p}$ & .672 & 1.000 & .048 & .421 & 1.000 & .951 \\
\hline
\end{tabular}

a There was no patient using biological practices

There was not a relationship between the CAM scale scores of the women and their employment status, educational status, income status, the history of a gynecological operation, presence of chronic diseases, being informed about the menopause period, and the frequency and duration of the complaints ( $\mathrm{p}>0.05)$. Using TAT among women affected by daily activities, referring to the doctor, living insomnia is more than rates $(\mathrm{p}<0.05)$.

\section{Discussion}

The average age of onset of menopause in the world African Health Sciences Vol 19 Issue 4, December, 2019 is reported to be 51 and it ranges from 45 to 55 years. In the developing countries, the mean age of onset of menopause is younger compared to that in the developed countries. The age of onset ranges from 49.3 to 51.4 years in the developed countries and from 43.5 to 49.4 years in the developing countries. For example; it is between 50 51 years in Jordan, 47 in Turkey, and 48 in Egypt. ${ }^{28}$ In this study, the average onset of menopausal age was found to be 46 in line with the previous studies.

It is reported that menopausal complaints are more common among women with obesity and any chronic diseases 
(such as hypertension, diabetes, cholesterol, etc.). ${ }^{29}$ In this study, complaints of hot flashes were found to be more severe in women who were in the obese group based on the BMI values. It was determined that hot flashes occurred most commonly on the back, followed by the head and neck region; and they were too disturbing to interrupt the sleep in the middle of the night, accompanied by sweating and palpitations. Studies have reported that hot flashes are typical for menopause and are accompanied by sweating. As they cause discomfort, it is recommended that they should be treated until they become tolerable. ${ }^{30}$ In the study of Saccomani et al, it was reported that especially the vasomotor, urinary, and joint symptoms were related to obesity in menopausal symptoms. It was also stated that in women with higher BMI values; hot flashes, urinary urgency, and vaginal dryness occurred at a significantly higher intensity. ${ }^{29}$

In this study, it was determined that a large majority of women practiced either deep breathing exercises (68\%) or physical exercises in order to cope with hot flashes. A large majority of women using these methods reported that they were effective $(72 \%)$. In the literature, the use of relaxation techniques is reported to be beneficial in relieving menopausal symptoms such as hot flashes since these methods help reduce sympathetic activation. Deep breathing is the simplest form of relaxation techniques. It is stated that a sufficient level of relaxation can be achieved, similar to the levels achieved with the diaphragmatic respiration techniques, reducing the frequency and severity of anxiety, depression, increased blood pressure, and hot flashes. ${ }^{23}$

Women attempt to try several modes of CAM to achieve resolution of their acute problems and to improve their quality of life. The popularity of CAM gradually increases day by day since it is cheap and easy to access, people feel insecure about the currently available treatments, the number of chronic diseases is on the rise, and people are more willing to take control and responsibility on the treatment of their disorders. ${ }^{31}$ In this study, it was determined that approximately 3 out of $4(72.6 \%)$ women in the menopause period tried CAM for the treatment of hot flashes. In some studies, CAM use rates of menopausal women were reported to be between $22-83 \%$. $^{32,33}$ In a literature review, it was stated that the rates of CAM use increased from $48.5 \%$ to $80 \%$, from 2002 to $2008 .{ }^{34}$ According to an analysis of 49 studies, it was reported that the CAM use rates in menopause was $70 \%$ and it was used beyond the health professional's knowledge. ${ }^{34}$ CAM is most commonly used for the treatment of most disturbing symptoms of menopause, especially for the treatment of hot flashes and insomnia. ${ }^{34,35}$ In this study, it was determined that more than half of the women had no information about the period of menopause, about two-thirds did not receive medical support, and the large majority of these women used CAM. These findings demonstrate that women use modes of CAM without the guidance and control of a healthcare professional.

Among women who did not receive information about menopause (from a health care provider, television or internet), herbal remedies were used more; and among those who received medical support, the use of nutritional supplements was more frequent. CAM use was more common among women who experienced disruptions in their daily life activities, who had insomnia, and who applied to a physician. Studies have indicated that women turned to CAM due to the side effects of Hormonal Replacement Therapies -HRT. Herbal medicines are widely used in Eastern Asian countries; especially in China, Korea, and Japan. However, there is not sufficient evidence on the efficacy and safety of these herbal remedies. It was stated that a mixture of Dang Gui Liu Huang Tang herbs was prescribed for the menopausal complaints including night sweats, fever, redness on the face, anxiety and feelings of discomfort, and dry mouth. It was also reported that this herbal mixture showed immunomodulatory and anti-inflammatory effects. ${ }^{36}$

Women using CAM for symptom management during the menopause preferred especially herbal products (leaves, stems, seeds, fruits, flowers, and roots).33 A study by Corzo et al. (2017) reported that E-MHK-0103, a natural alternative remedy and a nutraceutical lipoprotein extracted from Mytilus galloprovincialis, was found to be beneficial in relieving menopausal symptoms and could be used successfully in the clinical practice. ${ }^{37}$

In this study, it was determined that nutritional and religious approaches were also preferred besides the use of herbal products. From the herbal therapies; the simmered teas of linden, rosehip, daisy, green tea, and sage were most commonly used to cope with hot flashes. From the dietary supplements; fruits and vegetables, yoghurt, milk and milk products, and honey were most commonly used. In addition, it was determined that women practiced mind-body exercises and religious practices like ritual prayers of Islam, or simply prayed.

African Health Sciences Vol 19 Issue 4, December, 2019 


\section{Conclusion}

Hot flashes are commonly seen complaints in menopausal women. They were observed to be most common especially in the first year of menopause, occurring irregularly and at a frequency of 2-3 times a day and interrupting the daily activities of the large majority of menopausal women. It was observed that several methods were practiced by menopausal women to alleviate the hot flashes, including taking a luke-warm shower, moving to a cooler environment, wearing thin clothes, and performing deep breathing exercises. The use of CAM was more common among women, who received no information about the menopause period, who suffered from a relatively higher number of complaints, who applied to a physician, who received medical support, and who experienced interruptions in their daily life activities. It was determined that women especially preferred to use herbal remedies, nutritional supplements, mind-body exercises, and religious approaches to cope with hot flashes. A large majority of women using CAM reported that these practices were effective in alleviating the severity of their complaints.

Menopause is a transitional period and special care should be exercised in determining the healthcare needs of menopausal women. Women who use CAM methods often use these practices beyond the information of health professionals' knowledge and without being sufficiently informed. Further extensive studies are recommended to be conducted on these CAM methods and on their mechanisms of action. Health care providers should be actively involved in implementing sustainable educational programs and in assessing the needs of women in the menopause period.

\section{Conflict of interest}

None.

\section{Sources of funding}

None

\section{Contributorship of authors}

-Substantial contributions to the conception or design of the work; or the acquisition, analysis, or interpretation of data for the work; Ozcan H, Colak P, Oturgan B, Gülsever E.

-Drafting the work or revising it critically for important intellectual content; Ozcan $\mathrm{H}$

-Final approval of the version to be published; Ozcan H, Colak P, Oturgan B, Gülsever E.
-Agreement to be accountable for all aspects of the work in ensuring that questions related to the accuracy or integrity of any part of the work are appropriately investigated and resolved; Ozcan H, Colak P, Oturgan B, Gülsever E.

\section{References}

1. Timur S, Şahin N. Menopoz ve uyku. Maltepe Üniversitesi Hemsirelik Bilim ve Sanatı Dergisi 2010; 3(3): 62-67.

2. Chedraui P, Pérez-López FR, Aguirre W, et al. Beliefs regarding menopausal hot flushes among climacteric women as assessed with the hot flush beliefs scale. Maturitas 2010; 66: 298-304.

3. Vincent A, Barton DL, Mandrekar JN, et al. Acupuncture for hot flashes: a randomized, sham-controlled clinical study. Menopause 2007; 14: 45-52.

4. Freeman EW, Sherif K. Prevalence of hot flushes and night sweats around the world: a systematic review. Climacteric 2007; 10: 197-214.

5. Thurston RC, Christie IC, Matthews KA. Hot flashes and cardiac vagal control: a link to cardiovascular risk? Menopause. 2010; 17(3): 456-461.

6. Avis NE, Crawford SL, McKinlay SM: Psychosocial, behavioral, and health factors related to menopause symptomatology. Womens Health 1997; 3: 103-120.

7. Ho SC, Chan SG, Yip YB, et al: Menopausal symptoms and symptom clustering in Chinese women. Maturitas 1999; 33: 219- 227.

8. Guthrie JR, Dennerstein L, Hopper JL, et al: Hot flushes, menstrual status, and hormone levels in a population-based sample of midlife women. Obstet Gynecol 1996; 88: 437-442.

9. Hilditch JR, Chen S, Norton PG, et al: Experience of menopausal symptoms by Chinese and Canadian women. Climacteric 1999; 2: 164-173.

10. James CE, Breeson AJ, Kovacs G, et al: The symptomatology of the climacteric in relation to hormonal and cytological factors. Br J Obstet Gynaecol 1984; 91: 56-62.

11. Gold EB, Sternfeld B, Kelsey JL, et al: Relation of demographic and lifestyle factors to symptoms in a multi-racial/ ethnic population of women 40-55 years of age. $\mathrm{Am}$ J Epidemiol 2000; 152: 463-473.

12. Oğurlu N. :Kadınların Menopozal Yakınmaları ve Başetme Yöntemlerinin İncelenmesi. Adnan Menderes Üniversitesi, Sağlık Bilimleri Estitüsü, Doğum Kadın Sağlığ1 Hastalıkları Hemşireliği. Aydın, 2008.

13. Demirgöz M, Şahin N. Menopozal Sıcak Basması ve Alternatif Tedavi Seçenekleri. Göztepe Tip Dergisi 2008; 23(4): 143-148.

14. Baber R. The hot flush: symptom of menopause or 3007 
sign of disease? Climacterc 2017; 20(4): 291-292.

15. Bromberger JT, Matthews KA, Schott LL, et al. Depressive symptoms during the menopausal transition: the Study of Women's Health Across the Nation (SWAN).J Affect Disord 2007; 103: 267-72.

16. Cumming G, Currie H, Beck S, Moncur R. Provision of menopause information: do we get it right? A web-based survey on provision of menopause treatment information by health-care professionals to a computer-literate population accessing a menopause website. Menopause International 2011; 17: 112-113.

17. Stuenkel CA, Gass ML, Manson JE, et al. A decade after the Women's Health Initiative the experts do agree. Menopause 2012;19: 846-847.

18. Gollschewski S, Anderson D, Skerman H, Lyons-Wall P. Associations between the use of complementary and alternative medications and demographic, health and lifestyle factors in mid-life Australian women. Climacteric 2005; 8: 271-278.

19. Dhillon H, Zaki Nik Mahmood NM, Singh H. Documentation of self-care actions taken for somatic complaints by postmenopausal Malay women living in Kelantan Malaysia. Maturitas 2007; 58: 241-248.

20. Kupferer EM, Dormire SL, Becker H. Complementary and alternative medicine use for vasomotor symptoms among women who have discontinued hormone therapy. J Obstet Gynecol Neonatal Nurs 2009; 38: 50-59.

21. Lunny CA, Fraser SN. The use of complementary and alternative medicines among a sample of Canadian menopausal-aged women. J Midwifery Womens Health 2010; 55: 335-343.

22. Brett KM, Keenan NL. Complementary and alternative medicine use among midlife women for reasons including menopause in the United States: 2002. Menopause 2007; 14: 300-307.

23. Daley A, MacArthur C, McManus R, et al. Factors associated with the use of complementary medicine and non-pharmacological interventions in symptomatic menopausal women. Climacteric 2006; 9: 336-346.

24. Özcan H, Oskay Ü. Menopoz döneminde semptom yönetiminde kanıta dayalı uygulamalar. Göztepe T⿰р Derisi 2013; 28(4): 157-163.

25. Kargozar R, Azizi H, Salari R. A review of effective herbal medicines in controlling menopausal symptoms. Electronic Physician 2017; 9(11): 5826-5833.

26. Türkiye İstatistik Kurumu (Turkish Statistical Institute) http:/ / www.tuik.gov.tr/PreTabloArama.do?metod= search\&ara'Type $=$ vt. Accessed $=06.08 .2018$

27. Can G, Erol O, Aydiner A, Topuz E. Quality of life and complementary and alternative medicine use among cancer patients in Turkey. European Journal of Oncology Nursing 2009; 13(4): 287-294.

28. Gharaibeh M, Al-Obeisat S, Hattab J. Severity of menopausal symptoms of Jordanian women. Climacteric 2010; 13(4): 385-394.

29. Miller VM, Kling JM, Files JA, et al. What's in a name: are menopausal "hot flashes" a symptom of menopause or a manifestation of neurovascular dysregulation? Menopause 2018; 25(6): 700-703.

30. Saccomani S, Lui-Filho JF, Juliato CR, et al. Does obesity increase the risk of hot flashes among midlife women?: a population-based study. Menopause 2017; 24(9): 1065-1070.

31. Gökgöz N. Postmenopozal dönemdeki kadınların menopoz semptomlarına yönelik uyguladıkları tamamlayıcı ve alternatif tıp yaklaşımlarının yaşam kalitesine etkisi. University of Y1ldırım Beyazıt, Ankara, 2014.

32. Upchurch DM, Chyu MA. Use of complementary and alternative medicine among American women. Womens Health Issues 2005; 15: 5-13.

33. Gün Ç, Demirci N. Menopozda Bitkisel Tedavi Kullanım1. Archives Medical Review Journal 2015; 24(4): 520-530. 34. Taylor M. Complementary and Alternative Approaches to Menopause, Endocrinol Metab Clin North Am 2015; 44(3): 619-648.

35. Geller SE, Studee L. Botanical and dietary supplements for menopausal symptoms: what works, what doesn't. J Womens Health 2005; 14(7): 634-649.

36. Jun HJ, Lee HW, Zhang J, Yang F, Lee MS. Herbal medicine (Danggui Liuhuang decoction) for managing menopausal symptoms. Medicine (Baltimore). 2018; 97(4): 9735.

37. Corzo L, Rodriguez S, Alejo R, et al. E-MHK-0103 (Mineraxin $^{\mathrm{TM}}$ ): A Novel Nutraceutical with Biological Properties in Menopausal Conditions. Current Drug Metabolism 2017; 18(1): 39-49. 